\title{
Balance Scorecard Implementation Challenges in Institution of Higher Learning: Overview of Prior Studies
}

\author{
Peter U. Anuforo ${ }^{1}$, Hazeline Ayoup ${ }^{2} \&$ Nasiru Saidu $^{3}$ \\ ${ }^{1}$ Department of Accounting, University of Maiduguri Nigeria, Nigeria \\ ${ }^{2}$ Tunku Puteri Intan Safinaz School of Accountancy (TISSA-UUM), College of Business, Universiti Utara Malaysia, \\ 06010 UUM Sintok, Kedah, Malaysia \\ ${ }^{3}$ Department of Business Administration, Bauchi State University Gadau, Nigeria
}

Correspondence: Peter U. Anuforo, Department of Accounting, University of Maiduguri Nigeria, E-mail: peteru.love@gmail.com

Received: May 22, 2018

Accepted: May 30, 2018

Online Published: June 8, 2018

\begin{abstract}
The incessant decline in the performance of Malaysian public institution of higher learning since 2007 to date has brought to fore the question of its performance management process. Studies have shown that performance management is a general phenomenon in the institution of higher learning worldwide. The implementation issues of Balance scorecard (BSC) is more pronounced in the non-profit outfit and governmental organizations (NPGOs) compared to the profit-oriented outfit. Reasons being that the BSC was originally developed and (or) meant for the profit-oriented outfit and not exactly the other way round. The purpose of this paper is to provide insight into the issues of performance management in the institution of higher learning and specifically regarding the implementation issues of BSC encountered among Malaysia public institution of higher learning. This study provides a review of previous literature on the BSC implementation issues. Several implementation issues identified from the literatures are strategy misalignment, strategy communication issues, manager's acceptance/employees buy-in, the issue of clarity of vision, mission, strategy, and outcome, and strategy map implementation issues. Findings revealed that the implementation issues of the BSC among Malaysia public institution actually helps to unravel the pitfalls of BSC project and provides a roadmap show that can improve and sustain effective performance management. The implication of this study is aimed at providing the means by which the Malaysian public institution of higher learning can identify the issues inherent in BSC implementation or strategy implementation and the way forward.
\end{abstract}

Keywords: Balance scorecard, Malaysia Public Institution of Higher Learning, Performance Management, Strategy Alignment, Strategy Map.

\section{Introduction}

The incessant decline in the performance of Malaysian public institution of higher learning since 2007 to date has brought to fore the question of its performance management process. Studies have shown that performance management is a general phenomenon in the institution of higher learning worldwide. Thus, the main key determinant for success is "effective management"(Lee2006). In spite of the fact that the BSC has been developed for over 20 years now, it still suffers from several implementation issues coupled with its lack of standard rules for implementation especially in the non-profit outfit and governmental organizations (NPGOs). Therefore, understanding the cause of BSC implementation failure is fundamental to implementing a successful one. A good number of studies have indicated that organization that have decided to embark on adopting the BSC have encountered series of BSC implementation system issues such as manager's acceptance/employees buy-in, strategy misalignment etc.(Evans, 2005; Mac Phail, \&Halbert, 2005; Kaplan \& Norton, 2006a; Ayoup, Omar, \& Rahman, 
2015a). Studies on the challenges encountered in BSC implementation process is very scarce, as such, this study aims to fill the gap in the literature. Moreover, the purpose of this paper is to provide an insight into the issue of performance management in the institution of higher learning.

This research is structured as follows; section one outlines the overview of BSC concept, section two briefly discusses the BSC as a performance management system, section three gave a recap on the performance management in Malaysia institution of higher learning which serves as a basis for discussing BSC implementation in institution of higher learning; found in section four, and then section five research method, section six presents the core of the study which is BSC implementation issues, thereafter section seven conclusion and recommendations. Lastly section eight acknowledgements.

2. Overview of BSC Concept

According to Kaplan and Norton(1996), the four perspectives of BSC are basically the factor that affects the performance of the organization, as such the misalignment of these perspectives in the BSC implementation process will inevitably lead to failure of the organization's strategy. Each perspective of the BSC tries to answer vital performance question. The strategic alignment of BSC perspectives is regarded as fundamental because it serves as a building block of organizations performance, for example, Lee (2006), described the four perspectives of BSC as performance determinants as mentioned in his findings "there exist significant cause-effect relationships between performance determinants and the overall performance of the schools". Thus, the cause and effect relationship of BSC is a very vital determinant of the successful BSC implementation process. Although, studies such as Ittner, Larcker, and Randall, (2003a) reported that $75 \%$ of financial service firms ignored the cause and effect relationship of BSC perspectives.

3.The BSC as a Performance Management System

The BSC is regarded as one of the most influential contemporary performance management and measurement concept that aligns both short-term strategic actions and long-term strategic goals of institutions (Marr \&Schiuma, 2003; Anjomshoae, Hassan, Kunz, Wong, \& de Leeuw, 2017). The BSC model functions as both a performance measurement and management have attracted the interest of researchers, management scholars and practitioners since its introduction. It is used to measure the performance of both public and private sectors aimed at improving performance and achieving organization's key strategies and objectives (Zhijun, Zengbiao, \& Zhang, 2014; Shukri\&Ramli 2015; Gamal, \&Soemantri, 2017).The key vital element of BSC is that it provides a unique system for measuring and managing all the various aspects of an institution's performance and also plays the role of providing the needed clarity and specificity that makes firm's strategy, vision and mission statement meaningful, actionable and achievable. The implementation issues of BSC are more pronounced in NPGOs compared to the profit-oriented outfit. Reasons being that the BSC was originally developed and (or) meant for the profit-oriented outfit and not exactly the other way round. The failure rate in strategy implementation, especially in terms of BSC implementation in the recent years, is becoming alarming and uncalled for (Alexander 1985, Sterling 2003; Kaplan \&Norton, 2004;Kaplan, Norton, \& Barrows, 2008; Mankins \& Steele, 2005; Cândido\& Santos, 2015; Hu, LeopoldWildburger, \&Strohhecker, 2017).However, in spite of all the overwhelming impact of BSC on improving and sustaining firm's performance, the BSC still suffers a great deal of implementation issues leading to failure of the BSC project. For example, Atkinson (2006) reported that about 70\% of BSC implementation initiative failed over the years. Hence, the need to identify the causes of BSC implementation pitfall is very paramount, so as to eliminate or minimize the failure rate cases, which is the main motive of this study. Moreover, there is limited available evidence on studies that identified BSC implementation issues especially in the NPGOs.

4.Performance Management in Malaysia Institution of Higher Learning

In Malaysia, virtually all the institutions of higher learning are facing the issue of performance management, coupled with the rising height of competition both within and international academy arena. In a government research conducted between August 2006 and July 2007 on the assessment of the quality of Malaysian public universities, reports revealed that public institutions of higher education in Malaysia have been subjected under serious public scrutiny for failing to improve or at least emerge in international rankings with regards to offering outstanding education (Mohamed 2007; Azizan 2007; Ramachandran \& Foo 2007; Yu, Hamid,Ijab, \& Soo, 2009). Also, Binden, Mziu, andSuhaimi, (2014) reported that since the establishment of the Ministry of Higher Education (MOHE) in 2004 the Higher Education in Malaysia has become an important trend. Deliberate efforts have been made in several ways possible to support and develop higher education in Malaysia from different sectors of the economy be it the media, people and the government. Similarly, in order to ensure the existence of a conducive ecosystem, which will eventually catapult into knowledge and excellence. Thus, the ministry has introduced various policies to reinforce the national higher education. Specifically, before 2020 the government is strategizing an articulated effort towards making Malaysia the regional hub for higher education, as well as the main choice for international students and 
intellectuals. Moreover, how to go about achieving these targets is tasking considering the complexity of implementing the BSC project.

The performance system of the institution of higher learning is a multifaceted socialized system that requires a holistic approach. Thus, selection of appropriate performance management nowadays is very vital to the institution of higher learning because at the end of the day the outcome of the performance of such institution will determine the ranking profile of the university among its competing counterparts. For example, recently, there was a policy that was issued by the gov't of one of the African countries (i.e. Nigeria) regarding its student's enrolment in the Malaysian university. Five best Malaysian public universities were selected in this policy; as such this new policy affected the number of student's enrolment in any of the Malaysian university that fails to meet this criterion of "five best Malaysian universities". Consequently, the choice of appropriate performance management such as BSC and the strategic implementation process is fundamental to the success and improvement of the ranking profile of contemporary institutions of higher learning, especially among the public Malaysian universities.

Significant studies have provided evidence showing that BSC methodology is good performance management system especially when it is implemented properly (Davis \& Albright, 2003; Maiga \& Jacobs, 2003; Braam \& Nijssen, 2004; Kaplan \& Norton, 2006b). Studies also show that whether a BSC project is successful or not, heavily depends on how the BSC is being implemented, used and interpreted (Braam \& Nijssen, 2004; Madsen, \& Stenheim, 2014). Similarly, Danesh Haeri, and Jafari, (2017, p.1), reported that "the momentous issue, in the implementation of BSC, is the proper selection of measures".

5. BSC Implementation in Institution of Higher Learning

Kaplan and Norton introduced the concept of BSC in1990 and presented it as both a financial and non-financial performance measures (Karpagam \& Suganthi, 2012; Philbin, 2011; Taylor \& Baines, 2012). Articles on BSC have indicated the BSC model is particularly well-suited for the non-profit outfit and governmental organizations (NPGOs) (Niven 2008; Pietrzak, Paliszkiewicz \& Klepacki 2015; Praptapa, \&Yahya, 2016; Gamal, \& Soemantri, 2017). North cottand Taulapapa (2012) highlighted that the NPGOs adopted the private sector performance management model (i.e. the BSC) with the aim of improving and demonstrating their accountability and performance to the central government. Additionally, Dimitropoulos, Kosmas, and Douvis, (2017) stressed that the application of BSC model in public sector is due to its "ability to link financial performance measures with customer focus, the improvement of internal processes and the enhancement of innovation and learning". Moreover, Northcott and Taulapapa (2012) highlighted that BSC implementation in public organizations promotes and emphasizes performance excellence, enhances top management commitment, improves staff training and promotes clear organizational strategy and objectives. Although, one of the difficulty of implementing the BSC model is the need to modify the concept to reflect the peculiarity of the organization in question especially in terms of the institution's mission, vision, strategy, technology, and culture; otherwise the intended result or benefit may not be achieved (Kim, Suh, \& Hwang, 2003; Khomba, Vermaak, \& Hanif, 2012; Chimtengo, et al., 2017).Thus, to achieve a successful BSC implementation requires the proper articulation and implementation of the holistic framework of BSC as presented by Kaplan and Norton (Ayoup, et al., 2015a).

6. BSC Implementation Issues

BSC implementation issues basically stem from the causal linkage of organization vision and strategy that is embedded in the four perspectives of the BSC and how the strategies in each perspective are integrated. The BSC suffers from several implementation issues despite the claim that it is the most regarded contemporary strategic management accounting tools that helps in improving organization performance (Kaplan and Norton 1992, 1996, 2001, 2004 and 2006; Modell, 2012; Ayoup, et al., 2016). Several studies have also reported the significant positive impact of BSC implementation on firm performance (Hoque\& James, 2000; Malina \& Selto, 2001; Maiga \& Jacobs, 2003; Davis \& Albright, 2004; Braam \& Nijssen, 2004; Ayoup, et al., 2015). In general, significant numbers of studies have highlighted the challenges encountered in performance management system (PMS) implementation process to include among others communication strategy, support from information systems and top management, as well as employees/manager's involvement commitment, and coordination (Neely,Adams \& Crowe, 2001; Keating \& Harrington, 2003; Kwak \& Anbari, 2006; Fernandes, Raja \& Whalley, 2006; Umashev \& Willett, 2008;Martello, Watson \& Fischer, 2016). Although, several studies have attempted to focus on one or at most two issues of BSC implementation rather than focusing on the holistic view of the issues. To fill the gap in the literature, this paper aims to provide insight into the holistic cause of BSC implementation issues. Hence, the key issues that are associated with BSC implementation can be categorized under the following headings;

- Strategy misalignment

- Strategy communication issues

- The challenges of manager's acceptance/employees buy-in

- The issue of clarity of vision, mission, strategy, and outcome 
- Strategy map implementation issues

Note that the above issues are so much inter-related such that the failure of one automatically affects the implementation process. For example, regarding communication of organization's strategies between employees and management, findings by Trahant (2008) indicate that there is "a strong correlation between effective employee communication and superior organizational performance".

6.1 Strategy Misalignment

Strategic alignment within the context of this study refers to the alignment of organization's objectives, strategies, measures, targets and initiatives (Ayoup et al., 2016). Strategy alignment process involves the means (strategy map) by which the management communicates and streamline the organization's broad objectives in line with its mission, vision, and strategy. It also entails the alignment of both financial and non-financial measures and the cause and effect relationship among the BSC perspective measures.

In 2006, Kaplan and Norton introduced the concept of organizational alignment model which is aimed at curbing strategy misalignment in BSC implementation process (Ayoup et al., 2016). According to Skinner (1969), strategy misalignment is the missing link between "corporate level strategies and its different parts". Several studies have identified factors that affect strategic alignment (Nadler \&Tushman 1997; Melnyk, Calantone, Luft, Stewart, \& Zsidisin, 2005; Kathuria, Joshi, \&Porth, 2007). Moreover, one of the major issues of BSC implementation is strategy misalignment. For example, firms that implement BSC and is still experiencing low performance, in most cases the problem can be attributable to strategy misalignment among other issues (Bergeron, Raymond \&Rivard, 2004).

BSC as a strategic tool that promotes strategy alignment has brought to fore so many mixed results, especially among the practitioner and researcher. Contrary to the strategy misalignment that may be encountered during the course BSC implementation; the BSC facilitates the alignment of all facets of organization's objective by linking the mission, vision, and strategy (Kaplan \& Norton, 2006; Ayoup et al., 2016). Ayoup et al. (2016, p1) stressed that the organizational alignment model of Kaplan and Norton "is specially developed to complement the BSC implementation process in managing strategy misalignment". In spite of the model developed by Kaplan and Norton, the issue of strategic alignment still persist perhaps is due to the point raised by Schneiderman (2001) which suggest that "the key to linking strategic alignment is not the BSC itself, but the underlying processes that make it". Vaidyanathan (2005) supported this view by highlighting that understanding the links between organization's activities, resources, and the desired outcome promotes the implementation of organizational strategies.

The management of strategic alignment entails a change process (Kaplan \& Norton, 2006; Ayoup et al., 2015a). Thus, managing strategy misalignment involves "managing all organizational hard (such as the system, policies, and procedures) and soft elements" (Nadler \& Tushman, 1997; Ayoup, et al., 2016). Another cause of strategic misalignment is due to focusing on limited functional strategy and lack of utilizing the holistic strategic alignment framework of BSC during the implementation process (Ayoup, et al., 2015a). According to Ayoup, et al. (2015a) strategy misalignment may lead to "undesirable implications such as unaligned strategic objectives between the divisions; measures that may neither be fully understood nor implemented; targets could be compromised or unattainable; key initiatives and investments may not be prioritized, lack of optimal or inadequate funding which may require costly corrections". More so, the results of the findings of Ayoup et al. (2015b, p1) on factors affecting strategic alignment indicates that "top management commitment, effective communication, management intention, manager's acceptance to the system and its measures and trust have implications on successful BSC implementation and strategic alignment process". In addition, studies such as Decoene and Bruggerman (2006) also highlighted some negative impact of strategy misalignment on firm performance especially in terms of managers' intrinsic motivation on improving firm performance.

6.2The Issues of Manager's Acceptance/Employees Buy-in

To get the buy-in of employees is very vital because the employees are indispensable and integral part of every organizational function and are considered as the backbone of successful BSC implementation (Kaplan \& Norton 1996a; Kaplan \& Norton 2006b). In most cases, an organization that successfully implement BSC tend to be the ones in which their employees understand clearly the institution's strategy and vision (Slavica, et al., 2017). Thus, this is mostly being achieved by aligning employee's incentives and reward system with the institution's strategies. For example, some articles on BSC have identified the impact of lack of developing a suitable link between employees reward system and organization's KPIs (Ittner, Larcker\& Meyer, 1997; Roest 1997; Kaplan \& Norton, 2001, 2004; Chan 2004; Ayoup, et al., 2012). Also, in order to get the buy-in of employees/manager will involve achieving the objectives of the learning and growth perspective of BSC. Thus, this involves communicating the institutions' strategy to the employees, integrating the institution's strategy with the on-going management process and integrating employee's task and incentives to their reward system. Employees buy-in entails their involvement, commitment and dedication in the BSC implementation process (Ayoup, et al., 2016). The failure of the above- 
mentioned points may warrant and constitutes the pitfalls of BSC implementation strategy. For example, the findings of Malina and Selto (2001) show that if the BSC is not properly designed and implemented, it can actually de-motivate employees.

Issues involving employees/manager's buy-in can also arise as a result of poor management roles in the implementation process, lack of communication and commitment to the stipulated strategy (Aaltonen \& Ikavalko, 2002). The findings of Mayer and Gavin (2005) shows that employees' trust in managers and top management team enables them to focus more on value-producing activities. More so, strategic consensus between the manager and employees in BSC implementation process is very vital because according to Schaap (2012) strategic consensus fosters shared values and attitudes as well as enhances "frequent top-down and bottom-up communication within the organizational structure".

According to Ayoup et al (2015a), "the BSC provides a common frame of reference for all managers in making decisions and helps clarify the choices of performance measures that would strategically align the various components in a company". Also, the strategy map provides a clear presentation of organizational strategy to the manager but the issue encountered by the managers in most cases, is the difficulty of understanding the information provided and the usage (Ayoup, et al., 2016). According to De Waal and Coevert (2007), successful BSC implementation suffers, when a manager fails to understand that his role in the implementation process has a way of exerting an impact on organization's performance.

Essentially, Kaplan and Norton (2001) stressed that one of the main reasons that causes BSC implementation failure is due to lack of commitment on the part of the senior management team. Thus, manager's acceptance is vital because they are considered as the drivers and implementers of the BSC. Similarly, articles on BSC have indicated that the employees also are the key pivotal mechanism for success, especially in the service sectors, since they play a significant role in. virtually all the perspectives of BSC (Ittner,Larcker \& Randall 2003; Lau \& Sholihin 2005; Dimitropoulos, et al., 2017). Overall, Kaplan and Norton (2004) have identified that one of the critical success factor (CSF) of BSC implementation is getting adequate support from both managers and employees at all levels of the organization, hence anything short of this criterion may produce undesirable performance result. Although, the difficulty here, is how to cascade the strategies to the top-down individual managerial level.

In general, according to Dimitropouloset al. (2017, p17) "good preparation and training are very important for the proper implementation of BSC but the key element is dedication toward performance management starting from the top management to employees". Similarly, findings by Ferreira, (2017) while employing the qualitative case study approach supported this view, in that "findings suggests that the involvement of top manager and/or executive management is one of the critical success factors of the BSC project". Moreover, according to Kaplan and Norton (2001), the lack of this key element of dedication or commitment on the part of the senior team management to a large extent heavily affects BSC implementation project. Akin to this view is the study by Othman, Domil, Senik, Abdullah, and Hamzah (2008) on Malaysian organization which revealed some peculiar BSC implementation issues. One of the issues identified by Othman et al., (2008) regarding BSC implementation system in Malaysia organization is basically lack of support from managers. Similarly, a good number of studies have identified that manager's lack of knowledge and skills as well as the clear purpose of the organization's BSC implementation constitutes the bulk of BSC implementation failure (Moore 2003; Chan 2004; McPhail, Herington, \& Guilding, 2008; Ayoup, et al., 2012).

6.3Strategy Communication Issues

Strategy communication is described as "the process of communicating organizational strategic vision, mission, and corporate objectives to employees at all the levels of the organization management process (Kaplan \& Norton, 2001, 2006b)". According to Kaplan and Norton, (2001, p3), "nowadays, organizations need a language that serve as a medium of communicating strategy as well as information systems and processes that enable them to implement strategy and gain feedback about their strategy". In performance management system (PMS) implementation, communication has been regarded as one of the vital criteria for success (Beer \&Eisenstat, 2000; Ahn, 2001; Kaplan \& Norton, 2001, 2006; Atkinson, 2006; Ayoup, et al., 2016). Studies have indicated that during the course of strategy implementation process of BSC, strategy communication is heavily emphasized. Kaplan and Norton (2001) emphasized the critical role of BSC by highlighting that the BSC provides a framework of communication strategy that assist in aligning organizational strategy.

The issue of communication strategy in BSC implementation process can be addressed through proper and suitable adoption/adaption of the BSC (Atkinson, 2006). Merchant (1987) pointed out that communication failure is one of the major cause of weak strategy implementation. According to Malina and Selto (2001) effective organizational communication strategy includes providing valid message, knowledge sharing and supporting the organizational culture. Another issue encountered during the course of communicating organizational strategy in BSC implementation is the difficulty in documenting the detail processes and procedures of the BSC project (Ayoup et 
al., 2010). Also, the issue of how to communicate the content and process of the strategy (Ayoup, et al., 2016).Another overwhelming issue of BSC implementation system is the level of support and link between organizational information and communication system (Kaplan \& Norton's 2001; Richardson, 2004; Pandey 2005; Ayoup, et al., 2012).

6.4Improper Strategy Map Design and the Causal Model Development

The strategy map which functions as a causal relationship between the perspectives of BSC enables the managers to understand how outcome or lagging indicators or (i.e. financial and customer perspectives) are affected by performance drivers or leading indicators (process and learning and growth perspective) (Kaplan \& Norton, 2004; Park, et al., 2017). Kaplan and Norton (2004) also described the strategy map "as a pictorial diagram used by managers to explicitly describe their strategy and it cause-and-effect relationship among the four performance perspectives". Kaplan and Norton (2004) stressed that strategy map is one of the critical success factors of BSC implementation. Additionally, Othman (2006) outlined that the strategy map helps in supporting effective BSC implementation. On the contrary, significant criticism has been leveled against strategy map by both practitioners and researchers especially on the basis of its application.

Strategy map illustrates the causal relationship that links the internal business process and learning and growth as the drivers of the desired outcomes in customer and financial perspectives measures. The strategy map is regarded as the core and heart of BSC medium of communication, in the sense that any mistake or failure in the development process could eventually lead to miscommunication of strategy. Thus, the issues inherent in strategy map development includes; how to choose the best objectives from the list of strategy themes, measurability of the objectives, alignment of the selected objective with that of upper level division, cause and effect relationship linkage of the BSC perspectives, translation of the institutions' mission, vision and strategy into measures and objectives, managers' level of competency and commitment.

The strength and central idea of BSC lie in developing a strategic causal model, which according to Davis and Albright (2004) about $77 \%$ of BSC implementers in the USA recorded failure simply because of improper development of the causal model strategy. Although, Othman, (2008) stressed that one of the fundamental problems of the causal model strategy of BSC is rooted in the limitations of the strategy map as a tool that represents the causal relationship of organization's strategy. As a solution to the foregoing issue, Othman, (2008), suggested that understanding the causal relationship between the performance drivers and the desired outcomes is a prerequisite to developing a good strategic causal model.

The lack of standard rule in BSC implementation process constitutes a major challenge in developing a suitable strategy map because according to the originator of the concept, it has to be adopted and modified to reflect the peculiarity of the institution or organization concerned (Roest, 1997 and Kaplan \& Norton 2004). Similarly, studies have indicated that the lack of a specific method to guide organizations in developing a causal model of their strategy contribute to BSC pitfalls (Malmi, 2001; Speckbacher, Bischof, \& Pfeiffer, 2003; Othman, 2008). Although, Kaplan and Norton (1992, 2004, p5) outlined that in order to ensure successful implementation of strategy map "every organization" should implement their strategy map such that it will reflect the uniqueness and peculiarity of their organization' mission, vision, and strategy. Note that the failure of this stage of BSC implementation process will eventually lead to misalignment of organizational strategy, a breach in communication strategy, lack of clear vision, mission and strategy, and ultimately failure of employees/managers buy-in due to "missing link between strategy formulation and execution". Hence, the importance of the strategy map in BSC implementation cannot be overemphasized. More so, the improper implementation of the strategy map may render the strategic communication value of strategy map futile. Because fundamentally, the strategy map functions as a communication tool by which organization communicates their strategic vision and mission to all the managerial levels (Ayoup, et al., 2010).

6.5Lack of Clarity of Vision, Mission, Strategy and Outcome

Studies by Ahn (2001) indicated that failure in strategy formulation constitutes poor implementation of the strategy. Atkinson (2006) findings revealed that due to the issues encountered in BSC implementation, only as low as $30 \%$ BSC implementers derived its usefulness. Consistent with the findings of Atkinson is the survey result conducted by Rigby (2007), which shows that the level of satisfaction derived from BSC implementers is less than average. Beer and Eisenstat (2000) also identified that lack of clear strategy, misplaced priorities, and poor communication constitutes the issues of strategy implementation failure.

Several studies have indicated that lack of adequate awareness on the part of the employees to know the need to align the organization's strategy with objective constitutes BSC implementation issues (Langfield-Smith, 2008; Chan, Hons, Chan \&Okumus 2012; Mithas, Tafti, \& Mitchell, 2013; Ayoup, et al., 2015). Also, using the case study qualitative approach, the findings of Ayoup et al. (2015) revealed that three vital steps undertaken by the company to ensure strategic alignment in their BSC implementation process involves "creating awareness on the need for 
alignment, setting a common understanding of the issue and developing a systematic and formal implementation procedure", hence any deviation from this norm or strategy may constitute an unpleasant performance outcome.

According to Ayoup (2009), while employing the qualitative case study approach found out that the development of corporate mission and vision is essentially the starting point in BSC implementation process and also added that this is the stage that serves as "the basis for the top management of the company to develop its strategic company's direction or objectives and goal". Hence, any error at this level of BSC implementation process will constitute a serious implementation issue. In as much as there is lack of understanding of the BSC concept, with regards to the best measures applicable to a specific objective, failure is bound to occur regardless of whether the organization in question has fully adopted the BSC tools or not (Kaplan \& Norton 1992and Moore 2003).

\section{Research Methodology}

This paper aims to discuss previous research that is related to BSC implementation. Thus, this study is replete with prior studies on BSC which mainly focuses on BSC implementation issues. Moreover, this study provides an extensive literature review search, using the keywords "BSC implementation issues" to search for relevant extant articles and conference papers from different online database sources such as google scholar, research gate, emerald management plus etc. The articles used in this study are from reputable journal with high impact factor. Also, articles on BSC ranging from the inception of the concept (i.e. 1992) to 2018 were used in this study.

8.Conclusion and Recommendation

The purpose of this paper is to provide insight into the issue of performance management in the institution of higher learning and specifically regarding the implementation issues of BSC encountered among Malaysia public institution of higher learning. Also, the motivation of this study also gained weight since it is in response to the call for a future study by Dimitropoulos, et al., 2017).

Findings indicate that the major reason for the poor performance of BSC implementers especially among the Malaysian public institution of higher learning is due to the issues bordering the BSC implementation process. BSC implementation issues are so much inter-related such that the failure of one automatically affects the implementation process. And these issues include strategy misalignment, strategy communication issues, manager's acceptance/employees buy-in, the issue of clarity of vision, mission, strategy, and outcome, and strategy map implementation issues. Hence, this study serves as a basis to guide BSC adopters, especially among the Malaysian educational institution. Thus, identification of the issues bordering the BSC implementation process helps to provide an institution of higher learning with a more crystal clear view on how to successfully implement BSC devoid of any sort of flaws or at worst with minimal pitfalls. In other words, identifying the implementation issues of BSC is critical to successfully designing and developing a BSC system, particularly in the institution of higher learning. Additionally, the findings of this study indicate that a successful implementation of BSC depends solely in the organization's ability to identify the key issues inherent in the strategy implementation process, which invariably provides the organization with a better understanding of the BSC implementation project.

Moreover, findings show that the implementation issues of the BSC among Malaysia Public institution actually helps to unravel the implementation pitfalls of BSC which provides a roadmap showing how the institution of higher learning can improve and sustain effective performance management. Essentially, this finding supports the findings of Dimitropouloset al.,(2017) even though their study relates to BSC implementation in a "local government sports organization"

The implication of this study lies in both theoretical and practical contribution. This study provides a valuable insight into the main key issues of BSC implementation, particularly in the public sector. In other words, this study basically provides the means by which the Malaysian public institution of higher learning can identify the issues inherent in BSC implementation or strategy implementation and the way forward. Thus, the study sets a roadmap to show the implementing a hitch-free BSC that is devoid of the issues bordering the implementation process, hence ensures the sustenance of effective performance management

As a recommendation, understanding these key issues of BSC pitfall will assist in giving valuable insight to managers, especially those that are struggling with the BSC implementation process or other related management concepts. To achieve a successful BSC implementation requires the proper articulation and implementation of the holistic framework of BSC as presented by Kaplan and Norton. Moreover, based on the outcome of this study, as a prerequisite to implementing a successful BSC, it is highly recommended that institution of higher learning needs to identify the issues bordering its BSC implementation process so as to be able to derive the benefit arising from implementing a successful BSC model thereby improving and sustaining its overall performance.

The major limitation of this study stems from the conceptuality of the research. Thus, future studies should consider conducting the empirical study so as to ensure more detail investigations into BSC implementation pitfalls and dysfunctions because different types of BSC implementation issues can arise at a different point during the course of BSC implementation process, particularly in the NPGOs. 


\section{Acknowledgements}

I want express my sincere heartfelt gratitude to Dr. Hazeline Ayoup for her valuable input and contribution. This article would not have been possible without her resourceful supervision and guidance.

References

Aaltonen, P., \&Ikävalko, H. (2002).Implementing strategies successfully.Integrated Manufacturing Systems, 13(6), 415-418.

Ahn, H. (2001). Applying the balanced scorecard concept: an experience report.Long range planning, 34(4), 441461.

Alexander, L. D. (1985). Successfully implementing strategic decisions.Long range planning, 18(3), 91-97.

Al-Zwyalif, I. M. (2012). The possibility of implementing balanced scorecard in Jordanian private universities. International Business Research, 5(11), 113.

Anjomshoae, A., Hassan, A., Kunz, N., Wong, K. Y., \& de Leeuw, S. (2017). Toward a dynamic balanced scorecard model for humanitarian relief organizations' performance management.Journal of Humanitarian Logistics and Supply Chain Management, 7(2), 194-218.

Atkinson, H. (2006). Strategy implementation: a role for the balanced scorecard? Management Decision, 44(10), 1441-1460.

Ayoup, H. (2009). Observational Assessment of the Balanced Scorecard Strategic Alignment Process: A Study of a Utility Company.

Ayoup, H., Omar, N. H., \& Rahman, I. K. A. (2010, December). Strategy maps as a communication tool in Balanced Scorecard implementation: Study of a Malaysian utility company. In Science and Social Research (CSSR), 2010 International Conference on (pp. 48-52). IEEE.

Ayoup, H., Omar, N., \& Rahman, I. K. A. (2015a).Behavioural Factors Affecting Strategic Alignment Based on the Balanced Scorecard Framework: Evidence from A Malaysian Company.

Ayoup, H., Omar, N., \& Rahman, I. K. A. (2016). Balanced scorecard and strategic alignment: A Malaysian case. International Journal of Economics and Financial Issues, 6(4S).

Ayoup, H., Omar, N., \& Rahman, I. K. A. (2015b). Managing strategic alignment using the balanced scorecard: A Malaysian Company's experience.

Azizan, H. (2007).Ready for the big leap.The Star Newspaper. 18 November, http://thestar.com.my/news/story,asp?file=/2007/11/1/8/education/19484775\&sec=education

Beer, M., \&Eisenstat, R. A. (2000).The silent killers of strategy implementation and learning.Sloan management review, 41(4), 29.

Bergeron, F., Raymond, L. \&Rivard, S. (2003). Ideal patterns of strategic alignment and business performance.Information \& Management, 41, 1003-1020.

Bergeron, F., Raymond, L., \&Rivard, S. (2004). Ideal patterns of strategic alignment and business performance.Information \& management, 41(8), 1003-1020.

Binden, W., Mziu, H., \&Suhaimi, M. A. (2014).Employing the Balanced Scorecard (BSC) to Measure Performance in Higher Education-Malaysia.International Journal of Information and Communication Technology Research, 4(1).

Braam, G. J., \&Nijssen, E. J. (2004). Performance effects of using the balanced scorecard: a note on the Dutch experience. Long range planning, 37(4), 335-349.

Cândido, C. J., \& Santos, S. P. (2015). Strategy implementation: What is the failure rate?.Journal of Management \& Organization, 21(2), 237-262.

Cano, J. A., Vergara, J. J., \&Puerta, F. A. (2017). Design and implementation of a balanced scorecard in a colombian company. RevistaEspacios, 38(31).

Chan, Y. C. L. (2004). Performance Measurement and Adoption of Balanced Scorecards: A Survey of Municipal Governments in the USA and Canada, The International Journal of Public Sector Management, 17, 3: 204221.

Chimtengo, S., Mkandawire, K., \&Hanif, R. (2017).An evaluation of performance using the balanced scorecard model for the University of Malawi's Polytechnic.African Journal of Business Management, 11(4), 84.

DaneshAsgari, S., Haeri, A., \&Jafari, M. (2017).Integration of Balanced Scorecard and Three-stage Data Envelopment Analysis Approaches.Iranian Journal of Management Studies, 10(2), 527-550.

Davis, S. \& Albright, T. (2004). An Investigation of the Effect of Balanced Scorecard Implementation on Financial Performance, Management Accounting Research, 15: 135-153.

Decoene, V., Bruggeman, W. (2006), Strategic alignment and middle-level managers' motivation in a balanced score.International Journal of Operations and Production Management, 26(3-4), 429-448. 
DeWaal, A.A. \&Coevert, V. (2007). The Effect of Performance Management on the Organizational Results of a Bank, International Journal of Productivity and Performance Management, 56, 5/6: 397- 416.

Dimitropoulos, P., Kosmas, I., \&Douvis, I. (2017).Implementing the balanced scorecard in a local government sport organization: Evidence from Greece.International Journal of Productivity and Performance Management, 66(3), 362-379.

Evans, N. (2005). Assessing the Balanced Scorecard as a Management Tool for Hotels, International Journal of Contemporary Hospitality Management Accounting, 17, 5: 376-390.

Fernandes, K. J., Raja, V., \&Whalley, A. (2006).Lessons from implementing the balanced scorecard in a small and medium size manufacturing organization.Technovation, 26(5-6), 623-634.

Ferreira, A. M. S. C. (2017). How managers use the balanced scorecard to support strategy implementation and formulation processes. Tékhne-Review of Applied Management Studies, (1), 2-15.

Gamal, A., \&Soemantri, A. I. (2017).The Effect of Balanced Scorecard on the Private College Performance (Case Study at the University of WR Supratman Surabaya).Archives of Business Research, 5(5).

Hladchenko, M. (2015).Balanced Scorecard-a strategic management system of the higher education institution.International Journal of Educational Management, 29(2), 167-176.Hoboken NJ: John Wiley \& Sons Inc.

Hoque, Z., James, W. (2000), Linking balanced scorecard measures to size and market factors: Impact on organizational performance. Journal of Management Accounting Research, 12, 1-17.

Hu, B., Leopold-Wildburger, U., \&Strohhecker, J. (2017). Strategy map concepts in a balanced scorecard cockpit improve performance. European Journal of Operational Research, 258(2), 664-676.

Ittner, C. D., Larcker, D. F., \& Meyer, M. W. (1997).Performance, compensation, and the Balanced Scorecard.Unpublished, Wharton School, University of Pennsylvania, 1.

Ittner, C. D., Larcker, D. F., \& Randall, T. (2003a).Performance implications of strategic performance measurement in financial services firms.Accounting, organizations and society, 28(7-8), 715-741.

Ittner, C.D. \&Larcker, D.F. (2003b), "Coming up short on non-financial performance Measurement", Harvard Business Review, Vol. 81 No. 11, pp. 88-95.

Kaplan R.S. \& Norton D.P. (1992): The Balanced Scorecard - Measures that drive performance. Harvard Business Review, 70.1: 71-79.

Kaplan R.S. and Norton D.P. (1996): The Balanced Scorecard. Translating Strategy into Action.Mcgraw-Hill, Boston, MA.

Kaplan R.S. and Norton D.P. (2004): Strategy Maps: Converting Intangible Assets into Tangible Outcomes. Harvard Business School Press, Boston, MA.

Kaplan, A. M., \&Haenlein, M. (2010). Users of the world, unite! The challenges and opportunities of Social Media.Business horizons, 53(1), 59-68.

Kaplan, R. and Norton, D. (2001), "Transforming the balanced scorecard from performance measurement to strategic management: part I", Accounting Horizons, Vol. 15 No. 1, pp. 87-104.

Kaplan, R. S., \& Norton, D. P. (2006a). Alignment: Using the Balanced Scorecard to Create Corporate Synergies (Vol. 1). Boston Massachusetts: Harvard Business School Press.

Kaplan, R. S., \& Norton, D. P. (2006b). How to implement a new strategy without disrupting your organization.Harvard business review, 84(3), 100.

Kaplan, R. S., Norton, D. P., \& Barrows, E. A. (2008).Developing the strategy: Vision, value gaps, and analysis.Balanced scorecard report, 10(1), 1-5.

Karpagam, U. P., \&Suganthi, L. (2012).A strategy map of balanced scorecard in academic institutions for performance improvement.IUP Journal of Business Strategy, 9(3), 7.

Kathuria, R., Joshi, M. P., \&Porth, S. J. (2007). Organizational alignment and performance: past, present and future. Management Decision, 45(3), 503-517.

Keating, M., \& Harrington, D. (2003).The challenges of implementing quality in the Irish hotel industry.Journal of European Industrial Training, 27(9), 441-453.

Khomba, J. K., Vermaak, F. N., \&Hanif, R. (2012). Relevance of the balanced scorecard model in Africa: Shareholder-centred or stakeholder-centred?.African Journal of Business Management, 6(17), 5773.

Kim, J., Suh, E., \& Hwang, H. (2003).A model for evaluating the effectiveness of CRM using the balanced scorecard.Journal of interactive Marketing, 17(2), 5-19.

Kwak, Y. H., \&Anbari, F. T. (2006). Benefits, obstacles, and future of six sigma approach. Technovation, 26(5-6), 708-715.

Lau, C.M. and Sholihin, M. (2005), "Financial and non-financial performance measures: how do they affect job satisfaction?",British Accounting Review, Vol. 37 No. 4, pp. 389-413. 
Lee N (2006). Measuring the performance of public sector organisations: A case study on Public Schools in Malaysia.Measuring Business Excellence 10(4):50-64.

MacPhail, A., \&Halbert, J. (2005). The implementation of a revised physical education syllabus in Ireland: circumstances, rewards and costs. European Physical Education Review, 11(3), 287-308.

Madsen, D. Ø.,\&Stenheim, T. (2014). Perceived problems associated with the implementation of the balanced scorecard: evidence from Scandinavia.

Maiga, A. S., \& Jacobs, F. A. (2003). Balanced scorecard, activity based costing and company performance: an empirical analysis. Journal of Management Issues, 15(3), 283-301.

Malina, M. A., \&Selto, F. H. (2001). Communicating and controlling strategy: an empirical study of the effectiveness of the balanced scorecard. Journal of management accounting research, 13(1), 47-90.

Mankins, M. C., \& Steele, R. (2005).Turning great strategy into great performance.Harvard business review, 2607.

Marr, B., \&Schiuma, G. (2003).Business performance measurement - past, present and future.Management decision, 41(8), 680-687.doi:10.1108/00251740310496198

Martello, M., Watson, J. and Fischer, M. (2008), Implementing a Balanced Scorecard in a Not-for-profit Organization, Journal of Business and Economics Research, 6(9), pp.67-80.

Martello, M., Watson, J. G., \& Fischer, M. J. (2016).Implementing a balanced scorecard in a not-for-profit organization.Journal of Business \& Economics Research (Online), 14(3), 61.

Mayer, R. C., \& Gavin, M. B. (2005). Trust in management and performance: who minds the shop while the employees watch the boss? Academy of Management Journal, 48(5), 874-888.

McPhail, R., Herington, C., \&Guilding, C. (2008).Human resource managers' perceptions of the applications and merit of the balanced scorecard in hotels. International Journal of Hospitality Management, 27(4), 623-631.

Melnyk, S.A., Calantone, R.J., Luft, J., Stewart, D.M., \&Zsidisin, G.A. (2005).An empirical investigation of the metrics alignment process.International Journal of Productivity and Performance Management, 54(5/6), 312-324.

Merchant, K. A. (1987). How and why firms disregard the controllability principle. Accounting and management: Field study perspectives, 316-338.

Mithas, S., Tafti, A., \& Mitchell, W. (2013). How a firm's competitive environment and digital strategic posture influence digital business strategy. Mis Quarterly, 37(2), 511-536.

Modell, S. (2012), The politics of the balanced scorecard. Journal of Accounting and Organizational Change, 8(4), 475-489.

Mohamed, M. (2007). Plan to shape varsities of world class. The Star Newspaper, 14 November. http://thestar.com.my/news/story .asp?file=/2007/ 11/1 4/nation/ 1 9464095\&se

Moore, M. H. (2003). The Public Value Scorecard: A Rejoinder and an Alternative to Strategic Performance Measurement and Management in Non-Profit Organization by Robert Kaplan, Social Science Research Network Electronic Paper Collection, Retrieved from http://ssrn.com/ abstract=402880

Nadler, D.A.,\&Tushman, M.L. (1997). Competing by Design: The Power of Organizational Architecture.New York: Oxford University Press.

Neely, A., Adams, C., \& Crowe, P. (2001).The performance prism in practice.Measuring business excellence, 5(2), 6-13.

Niven, P.R. (2008). Balanced Scorecard Step-by-Step for Government and Nonprofit Agencies,organizational performance in the hotel sector.Tourism Management 26 (5),690-702.

Northcott, D. \&Taulapapa, T.M. (2012), "Using the balanced scorecard to manage performance in public sector organizations: issues and challenges", International Journal of Public Sector Management, Vol. 25 No. 3, pp. 166-191.

Othman, R. (2006). Balanced scorecard and causal model development: preliminary findings. Management

Decision, 44(5), 690-702.

Othman, R. (2008). Enhancing the effectiveness of the balanced scorecard with scenario planning.International Journal of Productivity and Performance Management, 57(3), 259-266.

Pandey, I. M. (2005). Balanced scorecard: myth and reality. Vikalpa,30(1), 51-66.

Papalexandris, A., Ioannou, G., \&Prastacos, G. P. (2004).Implementing the balanced scorecard in Greece: a software firm's experience.Long Range Planning, 37(4), 351-366.

Park, S., Lee, H., \&Chae, S. W. (2017). Rethinking balanced scorecard (BSC) measures: formative versus reflective measurement models. International Journal of Productivity and Performance Management, 66(1), 92-110.

Philbin, S. P. (2011). Design and implementation of the Balanced Scorecard at a university institute. Measuring Business Excellence, 15(3), 34-45. 
Pietrzak, M., Paliszkiewicz, J., \&Klepacki, B. (2015).The application of the balanced scorecard (BSC) in the higher education setting of a Polish university.Online Journal of Applied Knowledge Management, 3(1), 151-164.

Pongatichat, P., Johnston, R. (2008), Exploring strategy-misaligned performance measurement.International Journal of Productivity and Performance Management, 57(3), 207-222.Press, Boston, MA.

Praptapa, A., \&Yahya, M. A. B. The Use of Balance Scorecard for Performance Control: Case of Water Supply Company in Indonesia.

Ramachandran, S., \& Foo, H. (2007). Public universities fail outstanding test. New Straits Times, 6.

Richard, R.Y.Y., Yang, B., Lien, B.Y., McLean, G.N. \&Kuo, Y. (2009). Dynamic Capability: Impact of process alignment and organizational learning culture on performance. Journal of World Business, 401,1-10.

Richardson, S. (2004). The key elements of Balanced Scorecard success.Ivey Business Journal, 69(2), 7-9.

Rigby, D., \&Bilodeau, B. (2007).Management tools \& trends. Bain \& Company.Available at: http://www.bain.com/management_tools/home.asp.

Roest, P. (1997). The golden rules for implementing the balanced business scorecard.Information Management \& Computer Security, 5(5), 163-165.

Schaap, J. I. (2012). Strategy implementations-can organizations attain outstanding performance. Strategic Management Review, 6(1), 98-121.

Schneiderman, A. M. (2001). How to Build a Balanced Scorecard, part 3: Selecting Scorecard Metrics.

Shukri, N. F. M., \&Ramli, A. (2015). Organizational structure and performances of responsible Malaysian healthcare providers: A balanced scorecard perspective. Procedia Economics and Finance, 28, 202-212.

Skinner, W. (1969).Manufacturing- Missing Link in Corporate Strategy.Harvard Business Review, May- June, 1-10.

Slavica, T., Ljubica, K., \&Jelena, J. (2017).The modern concept of measuring efficiency-Implementation and attitudes of BSC.TEM JOURNAL-TECHNOLOGY EDUCATION MANAGEMENT INFORMATICS, 6(3), 525-533.

Speckbacher, G., Bischof, J., \& Pfeiffer, T. (2003).A descriptive analysis on the implementation of balanced scorecards in German-speaking countries.Management accounting research, 14(4), 361-388.

Sterling, J. (2003). Translating strategy into effective implementation: dispelling the myths and highlighting what works. Strategy \& Leadership, 31(3), 27-34.

Taylor, J., \& Baines, C. (2012). Performance management in UK universities: implementing the Balanced Scorecard. Journal of Higher Education Policy and Management, 34(2), 111-124.

Trahant, B. (2008). Six communication secrets of top-performing organizations.Public manager, 37(3), 68.

Turco, M. (2017). Development Perspective of Balance Scorecard through "multi-dimensional" value measurement. GSTF Journal on Business Review (GBR), 3(3).

Umashev, C., \& Willett, R. (2008). Challenges to implementing strategic performance measurement systems in multi-objective organizations: the case of a large local government authority. Abacus, 44(4), 377-398.

Vaidyanathan, S. (2005), Enterprise architecture in the context of organizational strategy.BPTrends, 9, 1-9

Yu, M. L., Hamid, S., Ijab, M. T., \& Soo, H. P. (2009). The e-balanced scorecard (e-BSC) for measuring academic staff performance excellence.Higher Education, 57(6), 813-828.

Zhijun, L. I. N., Y. U. Zengbiao, and Liqun Zhang."Performance outcomes of balanced scorecard application in hospital administration in China."China Economic Review 30 (2014): 1-15.

\section{Copyrights}

Copyright for this article is retained by the author(s), with first publication rights granted to the journal.

This is an open-access article distributed under the terms and conditions of the Creative Commons Attribution license (http://creativecommons.org/licenses/by/4.0/) 